Revista Latinoamericana de la Papa 22 (1): 67 - 75

ISSN: 1853-4961

http://www.papaslatinas.org/revista.html

\title{
Seleção de clones canadenses de batata para produtividade de tubérculos e qualidade de fritura no sul do Brasil
}

\section{G.O. da Silva ${ }^{1}$, A. da Silva Pereira ${ }^{2}$, F. Quintanilha Azevedo ${ }^{3}$, A.D. Ferreira de Carvalho $^{4}$}

Recebido: $24 / 11 / 2017$

Aceito: 06/04/2018

Acessiveis on-line: Junho 2018

\section{Resumo}

A cadeia brasileira de batata ressente-se da falta de cultivares adequadas para processamento, em especial com características para a fabricação de palitos pré-fritos congelados. O objetivo deste trabalho foi verificar o potencial de rendimento de tubérculos e a qualidade de fritura de clones de batata canadenses, para adaptação ao Sul do Brasil. Foi avaliado um conjunto de 33 clones pertencentes ao Centre de Recherche Les Buissons, QB, Canadá, e as cultivares Asterix, Atlantic e BRSIPR Bel. Os experimentos foram realizados em Pelotas, RS, e Canoinhas, SC, na primavera de 2016. ANOVA conjunta e individuais revelaram diferenças significativas entre genótipos. A interação $\mathrm{G}$ x E foi significativa para massa de tubérculos comerciais, número total de tubérculos, massa total de tubérculos, massa média de tubérculo e cor de "chips", e não significativa para número de tubérculos comerciais e peso específico. Em relação à massa de tubérculos comerciais, os clones foram agrupados dois conjuntos tanto em Canoinhas quanto em Pelotas, superando as três testemunhas no primeiro, e apenas 'Atlantic' no segundo. Quanto à qualidade fritura, isto é, peso específico e cor de "chips", dez clones se agruparam-se com as testemunhas em peso específico e simultaneamente estiveram no grupo superior de cor de "chips" nos dois locais. Os genótipos que melhor combinaram rendimento de tubérculos comerciais e qualidade de fritura em Canoinhas foram os clones 16, 10, 19, 14, 27 e 15, e em Pelotas foi o clone 10 e as cultivares Atlantic, Asterix e BRSIPR Bel. Concluiu-se que clones canadenses apresentam potencial de rendimento de tubérculos e qualidade de fritura para adaptação ao Sul do Brasil.

Palavras-chave adicionais: Solanum tuberosum L., rendimento de tubérculos, cor de fritura, peso específico.

\footnotetext{
* Autor para correspondência. Correspondência eletrônica: arione.pereira @embrapa.br

${ }^{1}$ Pesquisador da Embrapa, Canoinhas, Santa Catarina, Brasil.

${ }^{2}$ Pesquisador da Embrapa, Pelotas, Rio Grande do Sul, Brasil.

${ }^{3}$ Analista da Embrapa, Pelotas, Rio Grande do Sul, Brasil.

${ }^{4}$ Pesquisador da Embrapa, Gama, Distrito Federal, Brasil.
} 


\section{Selection of Canadian potato clones for tuber yield and fry quality in south of Brazil}

\section{Summary}

The Brazilian potato chain regrets the lack of suitable cultivars for processing, especially with characteristics for the manufacture of frozen French fries. The objective of this work was to verify the yield potential of tubers and the quality of frying of Canadian potato clones for adaptation to South of Brazil. A set of 33 clones belonging to the Center de Recherche Les Buissons, QB, Canada, and cultivars Asterix, Atlantic and BRSIPR Bel were evaluated. The experiments were carried out in Pelotas-RS and Canoinhas-SC, in the spring season of 2016. The $\mathrm{G} \times \mathrm{E}$ interaction was significant for commercial tuber mass, total tuber numbers, total tuber mass, mean tuber mass and chip color, and nonsignificant for number of commercial tubers and specific gravity. In relation to mass of commercial tubers, the clones were grouped in two sets, in Canoinhas and in Pelotas, overcoming the three checks in the first, and only 'Atlantic' in the second. Regarding the frying quality, that is, specific gravity and chip color, ten clones were grouped with the checks for the specific gravity and simultaneously were in the upper group of chip color at both sites. The genotypes that better combined yield of commercial tubers and frying quality in Canoinhas were clones 16, 10, 19, 14, 27 and 15, and in Pelotas were the clone 10 and cultivars Atlantic, Asterix, and BRSIPR Bel. It was concluded that Canadian potato clones have high yield potential and frying quality for adaptation to south of Brazil.

Additional key words: Solanum tuberosum L., tuber yield, fry color, specific gravity.

\section{Introdução}

A demanda por produtos industrializados de batata é crescente no Brasil, devido às mudanças nos hábitos alimentares, necessidade de se obter comida semipronta e produtos mais uniformes e práticos (Freitas et al. 2006). Há também, um aumento das cadeias de restaurantes, que demanda produto semiprocessado de batata de alta qualidade.

Em batata para o processamento industrial, os caracteres mais importantes são aqueles que conferem qualidade de fritura, tais como alto peso específico, baixo teor de açúcares redutores e ausência de distúrbios fisiológicos (Souza et al. 2011). O peso específico é um caráter importante, por ser diretamente relacionado com o teor de massa seca nos tubérculos (Schippers 1976), que mais elevada resulta em maior rendimento na industrialização, por menor absorção de gordura, melhor sabor do produto final (Smith 1975). O baixo teor de açúcares redutores evita o escurecimento dos produtos processados, que compromete a aparência e o sabor do produto frito (Stark \& Love 2003).

A indústria de batata no país se recente da falta de cultivares adequadas, em especial com características para a fabricação de palitos pré-fritos congelados. É sabido da expertise canadense em relação ao desenvolvimento de cultivares para processamento. No entanto, as condições de cultivo das diferentes regiões produtoras daquele país são diferentes em vários aspectos daquelas observadas no sul do Brasil. Na província de Quebec, devido às baixas temperaturas em alguns meses do ano, o cultivo de batata é realizado na primavera-verão, quando o fotoperíodo médio fica entre 16 a 18 horas de luz e as temperaturas entre 6 e $30^{\circ} \mathrm{C}$, enquanto no sul do Brasil são feitas duas safras principais, na primavera e no outono, visando escapar de temperaturas muito elevadas no verão e de geadas no 
inverno, e sob fotoperíodo médio próximo de 12 horas de luz e temperaturas entre 8 e $26^{\circ} \mathrm{C}$ nestes períodos. Em resposta ao fotoperíodo menor, a batateira apresenta redução do ciclo de desenvolvimento vegetativo, antecipação da tuberização e maior competição por fotoassimilados entre o crescimento vegetativo e o enchimento dos tubérculos. Além disso, com menor fotoperíodo ocorre menor produção de fotoassimilados e, consequentemente, menor rendimento de tubérculos (Pinto et al. 2010, Silva et al. 2012).

Dessa forma, o objetivo do presente trabalho foi verificar o potencial de rendimento de tubérculos e a qualidade de fritura de clones de batata de origem canadense, para adaptação ao sul do Brasil.

\section{Material e Métodos}

Foi avaliado um conjunto de 33 clones pertencentes ao Centre de Recherche Les Buissons - CRLB, Província de Quebec, Canadá, em comparação com três cultivares recomendadas para a fritura, Asterix, Atlantic e BRSIPR Bel.

Os experimentos foram realizados nos campos experimentais da Embrapa Clima Temperado, Pelotas, RS $\left(31^{\circ} \mathrm{S}, 52^{\circ} \mathrm{W}, 50\right.$ $\mathrm{m}$ a.n.m.), e da Embrapa Produtos e Mercado, Canoinhas, SC $\left(26^{\circ} \mathrm{S}, 50 \mathrm{~W}\right.$, 839 m a.n.m.), na primavera de 2016. Em Pelotas, o plantio foi realizado no dia 18 de agosto de 2016 e em Canoinhas em 24 de agosto de 2016. O delineamento experimental foi blocos casualizados com duas repetições de parcelas de duas linhas de 25 plantas, com espaçamento entre linhas de $0,75 \mathrm{~m}$ e entre plantas de 0,35 $\mathrm{m}$.

Como fertilizantes, foram aplicados no sulco de plantio 2,7 $\mathrm{t} \mathrm{ha}^{-1}$ da fórmula comercial NPK 05-20-10 em Pelotas, e
3,5 $\mathrm{t} \mathrm{ha}^{-1}$ da fórmula comercial NPK 0414-08 em Canoinhas. A amontoa foi realizada cerca de 30 dias após o plantio, e os demais tratos culturais e fitossanitários seguiram as recomendações da região (Pereira et al. 2010),

A colheita foi efetuada 100 dias após o plantio em ambos os locais. Os tubérculos de cada parcela foram classificados quanto ao diâmetro transversal em comerciais $(>45 \mathrm{~mm})$ e não comerciais ( $\leq 45 \mathrm{~mm})$, contados e pesados, obtendo-se os seguintes dados: massa total de tubérculos (kg parcela $\left.{ }^{-1}\right)$; massa de tubérculos comerciais ( $\mathrm{kg}$ parcela $\left.{ }^{-1}\right)$; número total de tubérculos; número de tubérculos comerciais; massa média de tubérculos (g), obtida da divisão da massa total de tubérculos pelo número total de tubérculos.

$\mathrm{O}$ peso específico foi medido em amostras de tubérculos de tamanho comercial, com utilização de hidrômetro da Snack Food Association (Arlington, VA, EUA). A cor de fritura foi acessada, utilizando amostras de três tubérculos sadios de tamanho comercial por parcela. Para isso, foram cortadas cinco fatias de cerca de 2,0mm de espessura de cada tubérculo e fritas em gordura vegetal à temperatura inicial de $180^{\circ} \mathrm{C}$ até cessar a borbulha. A cor de fritura foi avaliada atribuindo notas de 1 a 9 (1- escura, 9clara).

Os dados de massa de tubérculos foram convertidos em $\mathrm{t}^{-1}$ e de número de tubérculo foram convertidos em ha $1 / 1000$. Posteriormente, foi verificada normalidade da distribuição dos erros pelo teste de Lilliefors. Os dados de peso específico e cor de fritura foram transformados por $\sqrt{x+0,5}$. Foi realizada análise de variância individual e conjunta, e análise de agrupamento de 
médias por Scott \& Knott ao nível de 5\% de probabilidade do erro, utilizando-se o aplicativo computacional Genes (Cruz 2013).

\section{Resultados e Discussão}

As condições meteorológicas no período de cultivo em Canoinhas foram muito boas na primavera de 2016. A temperatura foi amena no final da estação, e as chuvas foram bem distribuídas durante todo o ciclo de desenvolvimento da cultura. Por outro lado, em Pelotas as condições meteorológicas também foram de temperaturas amenas durante o desenvolvimento da cultura, mas acompanhadas de precipitações pluviométricas bastante acima da média histórica, que favoreceram ocorrência da requeima.

As análises de variância conjunta e individuais revelaram diferenças significativas $(\mathrm{p}<0,05)$ entre genótipos (Tabela 1). A interação genótipo $\mathrm{x}$ ambiente $(\mathrm{GxE})$ foi significativa para massa de tubérculos comerciais, número total de tubérculos, massa total de tubérculos, massa média de tubérculo e cor de fritura, indicando que os genótipos tiveram comportamento diferente em Pelotas e Canoinhas para estes caracteres, e não foi significativa para número de tubérculos comerciais e peso específico.

Tabela 1. Resumo das análises de variância conjunta e individuais para caracteres de rendimento de tubérculos e de qualidade de fritura de 33 clones avançados e três cultivares testemunha de batata, na safra de primavera de 2016, em Canoinhas-SC e Pelotas-RS, Brasil.

\begin{tabular}{|c|c|c|c|c|c|c|c|c|}
\hline \multirow{2}{*}{$\begin{array}{l}\text { Fonte de } \\
\text { variação }\end{array}$} & \multirow[t]{2}{*}{ Gl } & \multicolumn{7}{|c|}{ Quadrado médio } \\
\hline & & MTC $^{1}$ & MTT & NTC & NTT & MMT & PE & COR \\
\hline \multicolumn{9}{|c|}{ Canoinhas + Pelotas } \\
\hline Genótipo (G) & 35 & $72,94 *$ & $80,21 *$ & $2485,64 *$ & $18510,43 *$ & $1298,40 *$ & $0,02 *$ & $0,26 *$ \\
\hline Ambiente (E) & 1 & $7974,34 *$ & $20543,25 *$ & 55422,58 & 434160,19 & $139210,45 *$ & 0,01 & $0,16 *$ \\
\hline$G \times E$ & 35 & $32,61 *$ & $33,20 *$ & 685,15 & $3622,35 *$ & $539,26 *$ & 0,01 & $0,05 *$ \\
\hline Resíduo & 70 & 15,33 & 19,71 & 580,11 & 2089,25 & 131,90 & 0,01 & 0,03 \\
\hline Média & - & 13,83 & 22,07 & 95,28 & 266,68 & 79,38 & 1,073 & 5,65 \\
\hline CV $(\%)$ & - & 28,31 & 20,12 & 25,28 & 17,14 & 14,47 & 0,07 & 7,06 \\
\hline $\mathrm{CVg} / \mathrm{CV}$ & - & 0,97 & 0,88 & 0,91 & 1,40 & 1,49 & 2,57 & 1,37 \\
\hline \multicolumn{9}{|c|}{ Canoinhas } \\
\hline Genótipo & $\begin{array}{l}3 \\
5\end{array}$ & $90,27 *$ & $92,22 *$ & $1728,68 *$ & $13659,01 *$ & $1525,97 *$ & $0,01 *$ & $0,15 *$ \\
\hline Resíduo & $\begin{array}{l}3 \\
5\end{array}$ & 26,03 & 32,73 & 746,22 & 2001,50 & 140,17 & 0,01 & 0,03 \\
\hline Média & - & 21,27 & 34,01 & 114,9 & 321,59 & 110,47 & 1,074 & 5,81 \\
\hline CV (\%) & - & 23,99 & 16,82 & 23,78 & 13,91 & 10,72 & 0,06 & 6,67 \\
\hline $\mathrm{CVg} / \mathrm{CV}$ & - & 1,11 & 0,95 & 0,81 & 1,71 & 2,22 & 3,06 & 1,49 \\
\hline \multicolumn{9}{|c|}{ Pelotas } \\
\hline Genótipo & $\begin{array}{l}3 \\
5\end{array}$ & $15,28 *$ & $21,20 *$ & $1442,11 *$ & $8473,77 *$ & $311,69 *$ & $0,01 *$ & $0,16 *$ \\
\hline Resíduo & $\begin{array}{l}3 \\
5\end{array}$ & 4,63 & 6,68 & 414,00 & 2177,01 & 123,62 & 0,01 & 0,03 \\
\hline Média & - & 6,39 & 10,12 & 75,66 & 211,77 & 48,29 & 1,073 & 5,49 \\
\hline $\mathrm{CV}(\%)$ & - & 33,69 & 25,54 & 26,89 & 22,03 & 23,03 & 0,08 & 7,45 \\
\hline $\mathrm{CVg} / \mathrm{CV}$ & - & 1,07 & 1,04 & 1,11 & 1,20 & 0,87 & 2,31 & 1,37 \\
\hline
\end{tabular}


De acordo com os valores do coeficiente de variação fenotípico, houve maior precisão no experimento de Canoinhas do que no experimento de Pelotas (Tabela 1). Os coeficientes de variação foram mais altos para os caracteres relacionados ao rendimento de tubérculos, com máximos para o caráter massa de tubérculos comerciais, de 24,99\% para Canoinhas e $33,69 \%$ para Pelotas. Caracteres como massa e número de tubérculos são quantitativos, os quais sofrem maior influência ambiental, portanto é esperado maior coeficiente de variação ambiental (Silva et al. 2006).

A relação entre o coeficiente de variação genético e coeficiente de variação ambiental $(\mathrm{CVg} / \mathrm{CV})$ foi superior a $80 \%$ para todos os caracteres (Tabela 1). Isto mostra a importância da variação de ordem genética em relação à ambiental, com situação favorável à seleção principalmente para número total de tubérculos, massa média de tubérculo, peso específico e cor de fritura, onde esta relação foi superior à unidade (Cruz et al. 2012).

Em relação à massa de tubérculos comerciais, que é o caráter mais importante componente do rendimento de tubérculos, tanto em Canoinhas quanto em Pelotas, foram agrupados em dois conjuntos (Tabela 2). Em Canoinhas, o grupo superior foi formado pelos clones $6,29,12,16,30,10,19,2,14,11,8,27$, 9,15 e 18, superando as três testemunhas, enquanto em Pelotas foi constituído pelos clones 6, 29, 30, 10, 23 e a cultivares Asterix e Bel, superando a 'Atlantic'. Portanto, os clones 6, 10, 29 e 30 foram coincidentes nos grupos superiores.

Quanto à massa total de tubérculos, em Canoinhas, o grupo superior foi constituído por maioria de clones do grupo de clones de maior massa de tubérculos comerciais e as três cultivares testemunhas (Tabela 2). Em Pelotas, o grupo superior foi constituído pelos mesmos clones do primeiro grupo de massa comercial e Asterix e Bel. 
Tabela 2. Agrupamento de médias de caracteres de rendimento para 33 clones canadenses e três cultivares comerciais de batata, avaliados na primavera de 2016, em Canoinhas-SC e PelotasRS, Brasil.

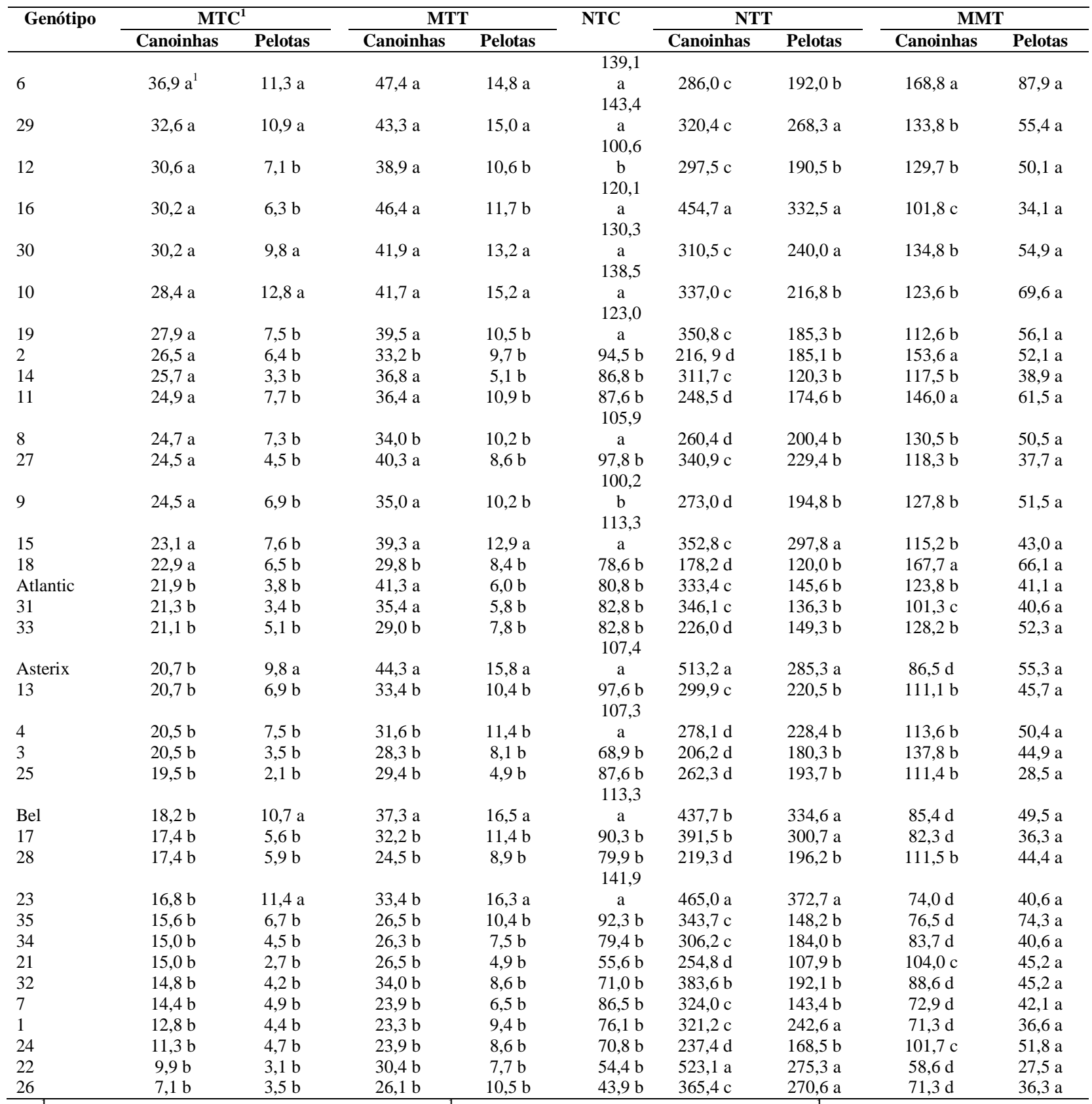

${ }^{1}$ MTC: massa de tubérculos comerciais $\left(\mathrm{t} \mathrm{ha}^{-1}\right)$; MTT: massa total de tubérculos ( $\left.\mathrm{t} \mathrm{ha}^{-1}\right)$; NTC: número de tubérculos comerciais $\left(\right.$ ha $\left.^{-1} / 1000\right)$; NTT: número total de tubérculos $\left(\mathrm{ha}^{-1} / 1000\right)$; MMT: massa média de tubérculo (g tubérculo ${ }^{-1}$ ). ${ }^{2}$ Médias seguidas pela mesma letra na coluna pertencem ao mesmo grupo pelo teste de Scott e Knott, a 5\% de probabilidade do erro.

No que tange a número de tubérculos comerciais, o grupo superior incluiu quatro clones $(6,29,30$ e 10), que estavam no primeiro grupo de massa de tubérculos comerciais em ambos os locais.

Em relação à massa média de tubérculos, em Canoinhas os clones formaram quatro 
grupos (Tabela 2). No grupo de maior massa média de tubérculos estiveram os clones 6, 2, 11 e 18, com valores variando de 168,8 a 146,0 g. Em Pelotas, os clones não formaram grupos.

No que se refere à média de peso específico, os clones formaram seis grupos (Tabela 3). A cultivar Atlantic formou isoladamente o primeiro grupo; os clones 27, 24, 15 e 9 constituíram o segundo grupo; e um conjunto de 15 clones e as testemunhas 'Bel' e 'Asterix' compuseram o terceiro grupo. $\mathrm{O}$ peso específico exerce grande influência na qualidade de fritura e no rendimento industrial, sendo em geral requisitado valor mínimo de 1,078 (Araújo et al. 2016), apresentado pelos clones 27, 24, 15, 9, 26 e 6, e as cultivares Atlantic e Bel.

Tabela 3. Agrupamento de médias de caracteres de qualidade de fritura para 33 clones canadenses e três cultivares de batata, avaliados na primavera de 2016, em Canoinhas-SC e Pelotas-RS, Brasil.

\begin{tabular}{|c|c|c|c|}
\hline \multirow[t]{2}{*}{ Genótipo } & \multirow[t]{2}{*}{ Peso específico } & \multicolumn{2}{|c|}{ Cor de "chips"1 } \\
\hline & & Canoinhas & Pelotas \\
\hline Atlantic & $1,087 \mathrm{a}^{2}$ & $7,5 \mathrm{a}$ & $8,0 \mathrm{a}$ \\
\hline 27 & $1,083 \mathrm{~b}$ & $7,5 \mathrm{a}$ & $6,3 \mathrm{a}$ \\
\hline 24 & $1,082 \mathrm{~b}$ & $6,0 \mathrm{a}$ & $7,0 \mathrm{a}$ \\
\hline 15 & $1,081 \mathrm{~b}$ & $7,0 \mathrm{a}$ & $5,5 \mathrm{~b}$ \\
\hline 9 & $1,080 \mathrm{~b}$ & $4,5 \mathrm{~b}$ & $5,3 \mathrm{~b}$ \\
\hline Bel & $1,078 \mathrm{c}$ & $9,0 \mathrm{a}$ & $7,8 \mathrm{a}$ \\
\hline 26 & $1,078 \mathrm{c}$ & $7,0 \mathrm{a}$ & $7,3 \mathrm{a}$ \\
\hline 6 & $1,078 \mathrm{c}$ & $5,5 \mathrm{~b}$ & $4,8 \mathrm{~b}$ \\
\hline 19 & $1,077 \mathrm{c}$ & $7,5 \mathrm{a}$ & 7,5 a \\
\hline 33 & $1,077 \mathrm{c}$ & $5,5 \mathrm{~b}$ & $5,5 \mathrm{~b}$ \\
\hline 16 & $1,076 \mathrm{c}$ & $6,5 \mathrm{a}$ & $5,8 \mathrm{a}$ \\
\hline 4 & $1,076 \mathrm{c}$ & $8,0 \mathrm{a}$ & $7,3 \mathrm{a}$ \\
\hline 31 & $1,076 \mathrm{c}$ & $7,0 \mathrm{a}$ & 7,3 a \\
\hline 14 & $1,076 \mathrm{c}$ & $6,5 \mathrm{a}$ & $5,5 \mathrm{~b}$ \\
\hline 29 & $1,075 \mathrm{c}$ & $5,0 \mathrm{~b}$ & $5,0 \mathrm{~b}$ \\
\hline 22 & $1,075 \mathrm{c}$ & $7,0 \mathrm{a}$ & $7,5 \mathrm{a}$ \\
\hline Asterix & $1,075 \mathrm{c}$ & $7,0 \mathrm{a}$ & $6,0 \mathrm{a}$ \\
\hline 10 & $1,075 \mathrm{c}$ & $6,0 \mathrm{a}$ & $6,8 \mathrm{a}$ \\
\hline 21 & $1,075 \mathrm{c}$ & $5,5 \mathrm{~b}$ & $4,0 \mathrm{c}$ \\
\hline 32 & $1,074 \mathrm{c}$ & $5,5 \mathrm{~b}$ & $3,8 \mathrm{c}$ \\
\hline 35 & $1,073 \mathrm{c}$ & $6,5 \mathrm{a}$ & $6,3 \mathrm{a}$ \\
\hline 30 & $1,073 \mathrm{c}$ & $5,0 \mathrm{~b}$ & $3,0 \mathrm{c}$ \\
\hline 3 & $1,072 \mathrm{~d}$ & $5,5 \mathrm{~b}$ & $4,0 \mathrm{c}$ \\
\hline 25 & $1,072 \mathrm{~d}$ & $4,0 \mathrm{c}$ & $4,0 \mathrm{c}$ \\
\hline 8 & $1,071 \mathrm{~d}$ & $6,0 \mathrm{a}$ & $5,0 \mathrm{~b}$ \\
\hline 1 & $1,071 \mathrm{~d}$ & $5,0 \mathrm{~b}$ & $4,0 \mathrm{c}$ \\
\hline 13 & $1,070 \mathrm{~d}$ & $6,0 \mathrm{a}$ & $6,3 \mathrm{a}$ \\
\hline 17 & $1,070 \mathrm{~d}$ & $5,0 \mathrm{~b}$ & $4,3 \mathrm{c}$ \\
\hline 2 & $1,069 \mathrm{~d}$ & $5,5 \mathrm{~b}$ & $3,8 \mathrm{c}$ \\
\hline 7 & $1,068 \mathrm{e}$ & $5,0 \mathrm{~b}$ & $5,0 \mathrm{~b}$ \\
\hline 11 & $1,067 \mathrm{e}$ & $4,0 \mathrm{c}$ & $5,3 \mathrm{~b}$ \\
\hline 18 & $1,067 \mathrm{e}$ & $4,0 \mathrm{c}$ & $4,5 \mathrm{~b}$ \\
\hline 34 & $1,066 \mathrm{e}$ & $2,5 \mathrm{~d}$ & $4,8 \mathrm{~b}$ \\
\hline 28 & $1,064 \mathrm{f}$ & $5,5 \mathrm{~b}$ & $5,0 \mathrm{~b}$ \\
\hline 23 & $1,061 \mathrm{f}$ & $4,5 \mathrm{~b}$ & $3,5 \mathrm{c}$ \\
\hline 12 & $1,061 \mathrm{f}$ & $4,0 \mathrm{c}$ & $5,5 \mathrm{~b}$ \\
\hline
\end{tabular}

${ }^{1}$ Cor de "chips" (notas de 1- escuro a 9- claro). ${ }^{2}$ Médias seguidas pela mesma letra na coluna pertencem ao mesmo grupo pelo teste de Scott e Knott, a 5\% de probabilidade do erro. 

No que tange à cor de "chips", em Canoinhas o grupo de clones de cor com média mais clara foi composto pelos clones 27, 24, 15, as três cultivares testemunhas, além de outros onze clones (Tabela 3). Em Pelotas, o grupo de melhor média foi formado pelos clones 27, 24, as três testemunhas e mais nove outros clones. Apesar dos efeitos significativos do fator ambiente e da interação $\mathrm{GxE}$, foi verificada uma grande similaridade entre os genótipos com médias superiores de cor de "chips" nos dois locais. Dos 16 genótipos superiores em Pelotas, 14 foram também superiores em Canoinhas.

Conjuntamente, para peso específico e cor de "chips", os clones pertencentes aos agrupamentos de média de peso específico das testemunhas e que simultaneamente fizeram parte do grupo superior de cor de "chips" dos dois locais, foram os clones $27,24,26,19,16,4,31$, 22,10 e 35.

Portanto, os genótipos que melhor combinaram rendimento de tubérculos comerciais e qualidade de fritura em Canoinhas foram os clones 16, 10, 19, 14, 27 e 15, e em Pelotas foi o clone 10 e as cultivares Atlantic, Asterix e BRSIPR Bel.

Os resultados deste estudo permitem concluir que clones canadenses apresentam potencial de rendimento de tubérculos e qualidade de fritura para adaptação ao Sul do Brasil.

\section{Conflitos de interesse}

Esta pesquisa não apresenta conflitos de interesse.

\section{Referências citadas}

Araújo, T.H.; Pádua, J.G.; Spoto, M.H.F.; Ortiz, V.D.G.; Margossian, P.L.; Dias, C.T.S.; Melo, P.C.T. (2016). Productivity and quality of potato cultivars for processing as shoestrings and chips. Hort. Bras. 34:554-560.

Cruz, C.D. (2013). Genes; a software package for analysis in experimental statistics and quantitative genetics. Acta Sci. Agron. 35:271-276.

Cruz, C.D.; Regazzi, A.J.; Carneiro, P.C.S. (2012). Modelos biométricos aplicados ao melhoramento genético. 4a. Edição. Editora UFV, Viçosa, MG, Brasil. 514 p.

Freitas, S.T.; Bisognin, D.A.; Gómeza, C.S.; Sautter, C.K.; Costa, L.C.; Rampelotto, M.V. (2006). Qualidade para processamento de clones de batata cultivados durante a primavera e outono no Rio Grande do Sul. Ciênc. Rural 36:80-85.

Instituto Brasileiro de Geografia e Estatística (IBGE). (2017). Produção Agrícola Municipal 2015: culturas temporárias. In: IBGE. http://www.sidra.ibge.gov.br/bda/pesquis as/pam/default.asp. Consulta: Junho, 2017.

Kumar, P.; Pandey, S.; Singh, B.; Singh, S.; Kumar, D. (2007). Influence of source and time of potassium application on potato growth, yield, economics and crisp quality. Potato Res. 50:1-13.

Pereira, A. da S. (org.). (2010). Produção de batata no Rio Grande do Sul. Embrapa Clima Temperado, Pelotas, RS, Brasil. 95 p.Pereira, A. da S.; Nazareno, N.R.X.; Silva, G.O.; Bertoncini, O.; Castro, C.M.; Hirano, E.; Bortoletto, A.C.; Treptow, 
R.O.; Dutra, L.F.; Lima, M.F.; Gomes, C.B.; Krolow, A.C.R.; Medeiros, C.A.B.; Castro, L.A.S.; Suinaga, F.A.; Lopes, C.A.; Melo, P.E. (2015). BRSIPR Bel: cultivar de batata para chips com tubérculos de boa aparência. Hort. Bras. 33:135-139.

Schippers, P.A. (1976). The relationship between specific gravity and percentage of dry matter in potato tubers. Am. Potato J. 53:111-122.

Silva, G.O. da; Pereira, A. da S.; Souza, V.Q. de; Carvalho, F.I.F. de; Neto, R.F. (2006). Early generation selection for tuber appearance affects potato yield components. Crop Breed. Appl. Biotechnol., 6:73-78.
Silva, G.O.; Castro, C.M.; Terres, L.R.; Rohr, A.; Suinaga, F.A.; Pereira, A. da S. (2012). Desempenho agronômico de clones elite de batata. Hort. Bras. 30:557560 .

Souza, Z.S.; Bisognin, D.A.; Junior, G.R.M.; Gnocato, F.S. (2011). Seleção de clones de batata para processamento industrial em condições de clima subtropical e temperado. Pesq. Agropec. Bras. 46:1503-1512.

Stark, J.C.; Love, S.L. Tuber quality. pp. 329-343. In: Stark, J.C.; Love, S.L. (eds.). (2003). Potato production systems. University of Idaho, Aberdeen, ID, Estados Unidos. 420 p. 